\title{
Primeros pasos para la conservación y puesta en valor del paisaje cultural de las bejeras en Larraga (Navarra)
}

\section{Joaquín Torres Ramoa y Verónica Quintanilla Crespo ${ }^{b}$}

${ }^{a}$ Universidad de Navarra. Departamento de Construcción, Instalaciones y Estructuras, Escuela de Arquitectura, 31009 Pamplona. jtorram@unav.es, ${ }^{\mathrm{b}}$ Arquitecto especialista en Restauración de Patrimonio, calle Florencio Ansoleaga, 14, 5 dcha., 31001 Pamplona. arquitectos@restauraciondepatrimonio.es

\begin{abstract}
Resumen
Situado en la zona media de Navarra, Larraga ha sido desde sus orígenes un pueblo dedicado fundamentalmente a la actividad agrícola. Entre las construcciones de carácter agropecuario diseminadas en su territorio, destacan por su singularidad las relacionadas con la producción apícola. Estas integran un sistema de edificaciones cuyo objetivo era alojar de manera estable enjambres de abejas: abejeras, celdas de aclimatación, ventureros, pozos y casetas buscan su acomodo en el territorio, abriéndose a la orientación más favorable. Sus características constructivas están ligadas a los materiales que provee el territorio y a técnicas tradicionales casi olvidadas.

Aunque hoy en día la actividad apícola casi ha desaparecido en Larraga, estos vestigios tienen un gran interés etnográfico y cultural. Constituyen un elemento de identidad de los propios habitantes, y son un referente de una economía ligada al territorio y a su sostenibilidad en el tiempo. Consciente de la importancia de su conservación, el Ayuntamiento comienza una serie de acciones con el objetivo de preservar este patrimonio, rico y singular, difundirlo y darlo a conocer. El presente artículo expone las conclusiones del trabajo realizado hasta el momento para la conservación y puesta en valor de este patrimonio, así como sus retos de futuro.
\end{abstract}

Palabras clave: paisaje cultural, conservación, territorio, arquitectura vernácula, abejeras, Larraga.

\begin{abstract}
Larraga is located in the centre of Navarra (Spain), on the banks of the River Arga. It has been a town mainly dedicated to agricultural production, since ancient times. Some rural buildings disseminated throughout its territory stand out for their singularity among all the constructions with agricultural character. They are some related to beekeeping activity. These constructions integrate an entire system of buildings whose objectives are to lodge stable swarms of bees: bejeras (beehives), acclimatization cells or ventureros, wells and huts seek their accommodation in the territory, opening to the most favourable orientation. Its constructive characteristics are linked to the materials provided by the territory and traditional techniques, almost disappeared.
\end{abstract}

Nowadays, although beekeeping activity has almost disappeared in Larraga, but these vestiges have a great ethnographic and cultural interest. They constitute an element of identity of Larraga population, and they are a referent of an economy linked to the territory and its sustainability over time. Aware of the importance of its conservation, the City Council has begun a series of actions with the aim of preserving this rich and unique heritage, spreading it and making it known. This article exposes the conclusions of the work carried out so far for the conservation and enhancement of this heritage, as well as its future challenges.

Keywords: cultural landscape, conservation, territory, vernacular architecture, beehives, Larraga. 


\section{Introducción}

La noción de paisaje cultural toma especial relevancia a partir de la Convención del Patrimonio Mundial de la UNESCO de París de 1992 (UNESCO, 1992) y, en Europa, a través del Convenio Europeo del Paisaje (Consejo de Europa, 2000). En noviembre de 2012 se firma en Cartagena de Indias la conocida como Carta Iberoamericana del Paisaje Cultural, una serie de recomendaciones conducentes a reconocer su importancia en el desarrollo integral y sostenible de la población, la mejora de la calidad de vida y el reforzamiento de su identidad (UNESCO, 2012).

El paisaje cultural es entendido como el resultado de la interacción en el tiempo de las personas y el medio natural, cuya expresión es un territorio percibido y valorado por sus cualidades culturales, producto de un proceso y soporte de la identidad de una comunidad. En este sentido, el paisaje cultural ha de considerarse un sistema dinámico, resultado de procesos ambientales, sociales, económicos y culturales que se han sucedido a través del tiempo ${ }^{1}$. Y en ese mismo sentido, los paisajes culturales deben ser sostenibles, es decir, se deben poder mantener a sí mismos en el tiempo, sin pérdida de sus cualidades ${ }^{2}$; más aún, con la capacidad de convertirse en un verdadero recurso de desarrollo (UNESCO, 2012).

El paisaje de la zona media de Navarra cuenta con numerosos elementos propios de la tradición agrícola, la cual ha constituido su principal actividad económica hasta nuestros días. Algunos de estos elementos se han ido adaptando a las nuevas exigencias productivas, mientras que otros nos han llegado como testigos presenciales de un momento pasado que nos ayudan a entender mejor el presente y que forman parte del imaginario cultural colectivo.

En el entorno del municipio de Larraga, como en tantos otros lugares de nuestra geografía, se conservan una serie de pequeños edificios integrados en el paisaje que hablan de su actividad agrícola y ganadera preindustrial. Entre ellos destacan por su singularidad los conocidos como bejeras (abejeras) y otras construcciones relacionadas con la actividad apícola. La singularidad de estas pequeñas construcciones, su interés etnográfico, arquitectónico y constructivo las convierten en un importante objeto patrimonial; y el paisaje en el que se insertan englobable en la categoría de Paisaje Cultural tal y como viene definida en la Ley Foral de Patrimonio Cultural de Navarra (Ley Foral 14/2005).

Desde una visión holística del patrimonio, estas construcciones están dotadas de un gran valor documental, en cuanto que son un legado histórico construido; de valores arquitectónicos y paisajísticos de interés; y de un fuerte valor significativo e identitario para los habitantes de Larraga, especialmente entre aquellas generaciones de más edad. Todo ello las convierte en elementos patrimoniales potencialmente destacables y sobre los que merece la pena llamar la atención.

\section{Objeto del proyecto}

\subsection{Las bejeras de Larraga}

Las bejeras (abejeras) son construcciones tradicionales propias de la zona media de Navarra (España) que en el término municipal de Larraga se han conservado en gran número (Fig. 1). Cada bejera la forman un conjunto de colmenas agrupadas en un habitáculo rectangular de piedra, la bejera propiamente dicha, situado al abrigo de una pequeña colina y orientadas al sur. Habitualmente se encuentran acompañadas de otras construcciones auxiliares como son las celdas de aclimatación o ventureros y alguna caseta para refugio. Se localizan próximas a un pozo, riachuelo o balsa y rodeadas de árboles con flor (como se muestra en la figura 2) donde las abejas pueden libar el néctar: almendros, pomeros, nogales, higueras o melocotoneros.

\subsection{Características constructivas}

Todas estas bejeras presentan características arquitectónicas y constructivas similares, propias de la tradición constructiva local agrícola (Figs. 3 y 4):

\footnotetext{
${ }^{1}$ Carta Iberoamericana del Paisaje Cultural, 2012. I. Definiciones.

${ }^{2}$ Ídem.
} 
- Uso de la piedra arenisca local, que permite la extracción en grandes lajas. La existencia de abundantes afloraciones rocosas en todo el territorio y algunas particularmente cercanas a la ubicación de muchas bejeras apunta a que éstas fueron utilizadas como cantera para su construcción.

- Empleo de sistemas constructivos adintelados básicos: sucesiones de pórticos apoyados formando por trilitos; falsas bóvedas y falsas cúpulas mediante lajas apoyadas unas en otras, etc.

- Uso de arcilla como aglomerante para asentar las fábricas.

- Cubiertas de tierra.

En su ubicación y relación con el entorno, todas comparten:

- Orientación adecuada al uso: sur-suroeste para la fachada principal de la bejera.

- Ubicación en las proximidades de masas naturales de agua. Cuando esto no es así, hay que proveer a la bejera de un pozo de recogida.

En un análisis comparativo, son construcciones singulares y tipológicamente distintas de otras construcciones apícolas más extendidas en ámbitos geográficos próximos o no tan próximos (Figs. 5 y 6). Por un lado, los materiales de construcción propios del lugar y el empleo que se hace de ellos, junto con la optimización del espacio derivada tanto del uso como de la resolución constructiva, desemboca en la consolidación de un tipo de edificio muy característico.

A su vez, cada una de ellas presenta singularidades relacionadas con:

- Su tamaño. Las más pequeñas apenas tiene $3 \mathrm{~m}$ lineales de fachada, las mayores alcanzan $15 \mathrm{~m}$.

- Su implantación en el medio, generalmente al refugio de los vientos.

- Su relación espacial con otras construcciones auxiliares próximas: casetas, ventureros o celdas de aclimatación, pozos, muros de piedra, etc.

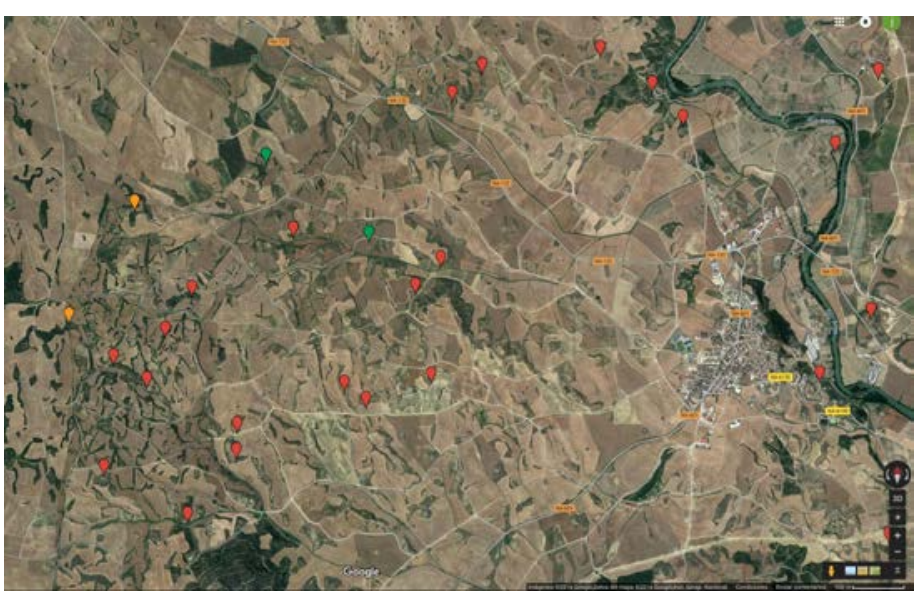

Fig. 1 Localización de las bejeras en el territorio

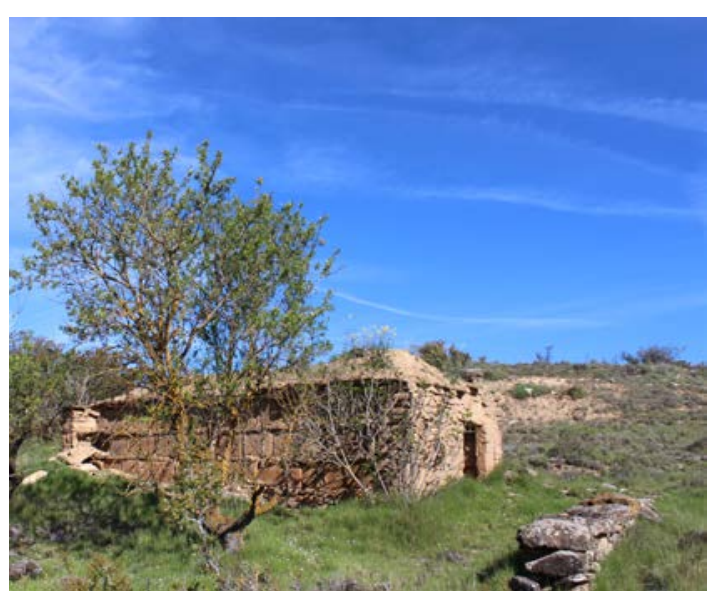

Fig. 2 Una de las bejeras en su entorno

\subsection{Estado de conservación}

En el momento en el que se realiza el proyecto, el estado de conservación es muy diferente de unas a otras. La mayoría de ellas están sin actividad, lo que ha propiciado su abandono y falta de mantenimiento. Algunas se encuentran parcialmente derruidas (Fig. 7), lo que contribuye a que su deterioro avance progresivamente, llegando algunas de ellas prácticamente a haber desaparecido, como las celdas de aclimatación que muestra la figura 8.

El estado de conservación fue un factor determinante a la hora de plantear las prioridades de actuación. Hoy en día, todavía quedan muchas bejeras que necesitan una intervención de consolidación y, sobre todo, un mantenimiento que les permita perdurar en el tiempo. 


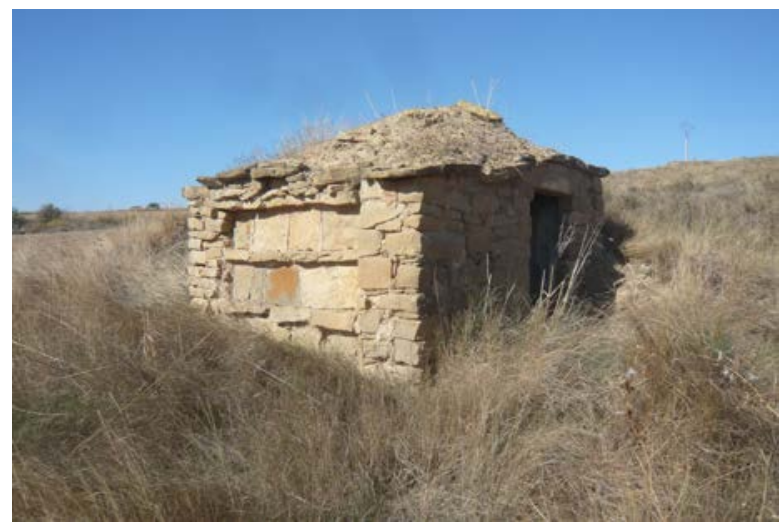

Fig. 3 Bejera de pequeño tamaño

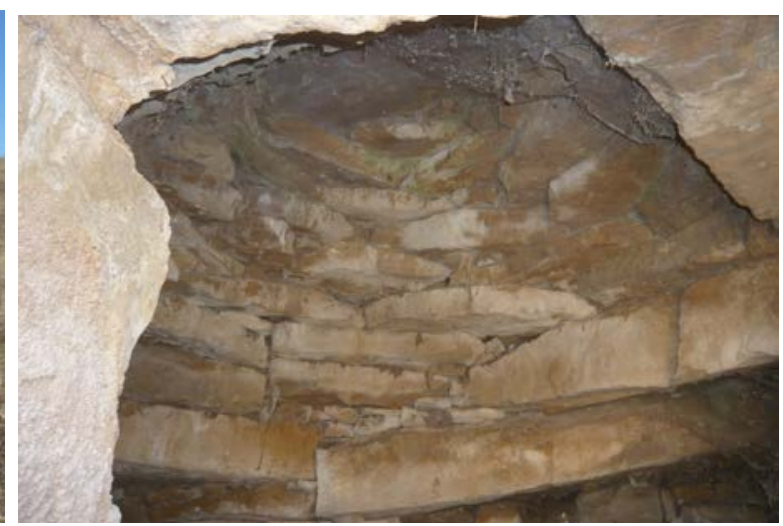

Fig. 4 Falsa cúpula que forma el techo de la bejera

\section{Metodología y criterios de intervenciónAntecedentes y punto de partida}

En diciembre de 2015 se presentó el documento Propuesta de Intervenciones en Patrimonio_Larraga, promovido por el Ayuntamiento de esta localidad en el que se establecía un diagnóstico de la situación actual, analizando las necesidades de usos y las potencialidades de los diferentes espacios y edificios patrimoniales del municipio. Con ello, se marcaba una propuesta de actuación, estableciendo objetivos a corto, medio y largo plazo; y se señalaban una serie de acciones transversales encaminadas a la difusión y divulgación del patrimonio en relación con las actuaciones materiales fijadas.

Entre las propuestas a corto plazo se señalaba la intervención de conservación y difusión de las bejeras de Larraga. Se remarcaba el interés por consolidar las construcciones existentes en su ubicación natural. Se resaltaba la importancia de darlas a conocer, como la herramienta más eficaz para su puesta en valor y, en consecuencia, su persistencia; $\mathrm{Y}$ se planteaba su catalogación para dotarlas de un grado de protección a nivel administrativo.

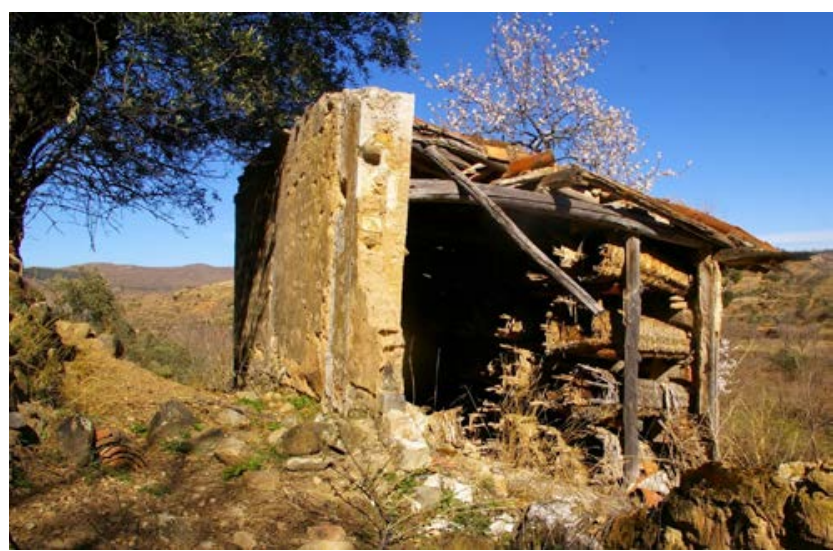

Fig. 5 Abejera de Préjano (La Rioja)

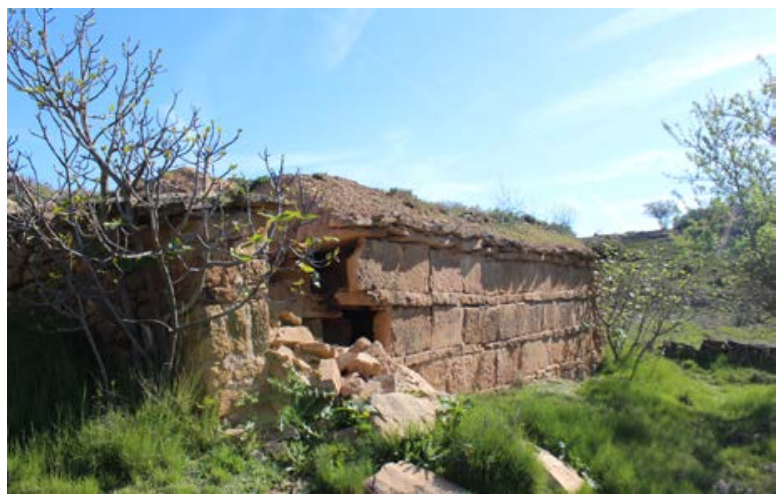

Fig. 7 Bejera parcialmente destruida

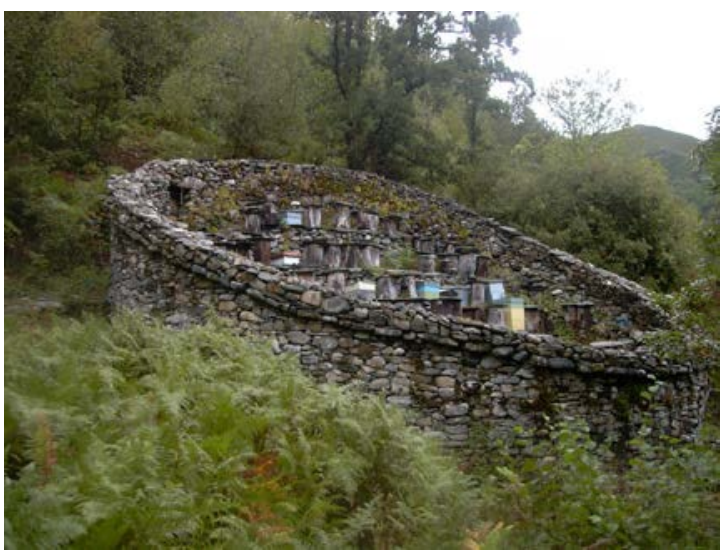

Fig. 6 Reserva de la Biosfera de Muniellos (Asturias)

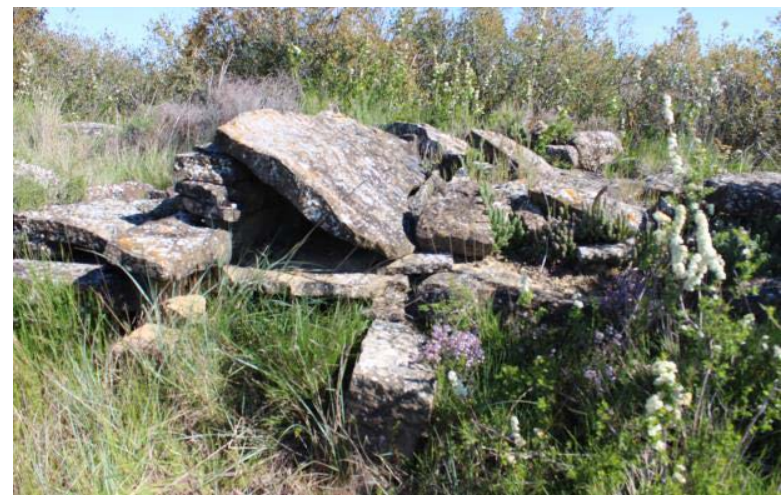

Fig. 8 Ventureros totalmente derruidos 


\subsection{Objetivos y puesta en marcha}

En 2016 el Ayuntamiento decide acometer un proyecto que desarrolle los objetivos que se establecían en la Propuesta de Intervenciones en Patrimonio, de 2015, para las bejeras. El objetivo principal planteado por el Ayuntamiento de Larraga supone estudiarlas y darlas a conocer para que no se pierdan, ya que forman parte de la tradición y de la vida de los ragueses: Es un patrimonio cultural que merece la pena conservar, y para ello debe ser valorado por los propios ragueses y también conocido fuera de la localidad.

Para ponerlo en valor es necesario que la gente sepa cómo funcionan estas construcciones. El primer paso en esta dirección es completar y contextualizar la bejera que recientemente había sido trasladada al parque de los Turrientes, dotándola de un entorno apropiado, que incluya las edificaciones auxiliares que le faltan y colocando paneles explicativos que hagan didáctica la visita tanto para pequeños como para mayores.

Los siguientes pasos van encaminados a dar a conocer las bejeras existentes en su propio entorno natural. Para ello, se plantea una serie de recorridos señalizados. También la realización de una serie de acciones de difusión y divulgación del paisaje cultural de las bejeras.

A la vez, se aboga por la catalogación y protección de estas construcciones a través de su consideración en el catálogo del nuevo Plan Municipal de Larraga ${ }^{3}$. El objetivo es que desde la administración se pueda velar por la conservación de este patrimonio, aunque se tiene claro que de poco sirve si no se consigue crear entre los propios ragueses usuarios de estas construcciones un sentimiento de interés hacia ellas.

\subsection{Criterios metodológicos y de intervención}

En octubre de 2016 se presenta un proyecto que desarrolla dos ejes de actuación complementarios: la creación de un espacio de interpretación en el paraje de Los Turrientes, aprovechando sus potencialidades. Y la consolidación de las construcciones existentes en el territorio estableciendo una serie de recorridos señalizados que conecten varias de las bejeras existentes.

Al mismo tiempo se van dando pasos en la documentación de las construcciones, y se valora las pautas administrativas para una futura catalogación de estos bienes. En este punto sirvió de partida el trabajo realizado por J.M. Nieto (Nieto García, 2011).

Metodológicamente se toma como referencia el Plan Nacional de Paisaje Cultural (Carrión Gútiez, 2015), aun cuando el proyecto que nos ocupa no se ha beneficiado directamente de este Programa. Los Planes Nacionales impulsados desde el Instituto del Patrimonio Cultural de España (Ministerio de Educación, Cultura y Deporte) se articulan con la vocación de servir como instrumentos de gestión mediante el desarrollo de criterios y metodologías de actuación unificados sobre conjuntos de bienes culturales, coordinando la participación de las distintas administraciones e instituciones, definiendo criterios de intervención y optimizando los recursos de acuerdo con las necesidades de conservación de esos conjuntos patrimoniales. En este caso, el Plan Nacional de Paisaje Cultural, aporta criterios de identificación, valoración y selección que se adoptan en el proyecto.

\footnotetext{
${ }^{3}$ En Navarra, según establece la propia Ley Foral 14/2005 de Patrimonio Cultural, La declaración de un bien inmueble como Bien de Relevancia Local se produce por su inclusión en los Catálogos de planeamiento urbanístico elaborados por las entidades locales, con el informe favorable por parte del Departamento competente en materia de cultura (Cf. art. 22). Son Bienes de Relevancia Local aquellos bienes inmuebles del Patrimonio Cultural de Navarra que, sin reunir las condiciones para ser declarados como Bienes de Interés Cultural o Bienes Inventariados, tengan significación cultural a nivel local y sean declarados como tales conforme al procedimiento establecido en esta Ley Foral. Sería el primer paso para una posterior consideración como Bienes inmuebles de Interés Cultural en la categoría de Paisaje Cultural.
} 


\section{Primera fase de intervención}

\subsection{El parque de los Turrientes: Espacio de interpretación de las Bejeras de Larraga}

El parque de los Turrientes de Larraga es un espacio llano a la entrada del núcleo urbano (Fig. 9), resultado de sucesivos vertidos sobre la ladera que acompaña a la Cañada Real en su descenso hacia el río. La intervención en el parque de los Turrientes se encamina a contextualizar la bejera trasladada a esa ubicación (Figs. 10 y 11). Para ello:

- Se construye una caseta, celdas de aclimatación y un pozo de recogida de aguas de escorrentía (pequeñas construcciones agrícolas relacionadas con ella).

- Se modifica la topografía, creando un pequeño promontorio artificial que resguarde esas construcciones, apoyándose sobre él.

- Se crean diferentes ámbitos de estancia (bejera, mirador, cañada real...) mediante la manipulación del terreno y el uso de especies de vegetación autóctona, propia del lugar.

- El Espacio de interpretación de las Bejeras de Larraga en el parque de los Turrientes se plantea también como el origen de diferentes rutas que permitan conocer algunas de las bejeras existentes en el término municipal.

Con ello, además, se busca potenciar las cualidades paisajísticas de la zona de los Turrientes, dando la espalda a la carretera y a las naves agrícolas que la circundan y favoreciendo las vistas hacia el valle del Arga (Fig. 12). Para facilitar la lectura y comprensión del lugar y sus construcciones, se colocan unos sencillos paneles explicativos.

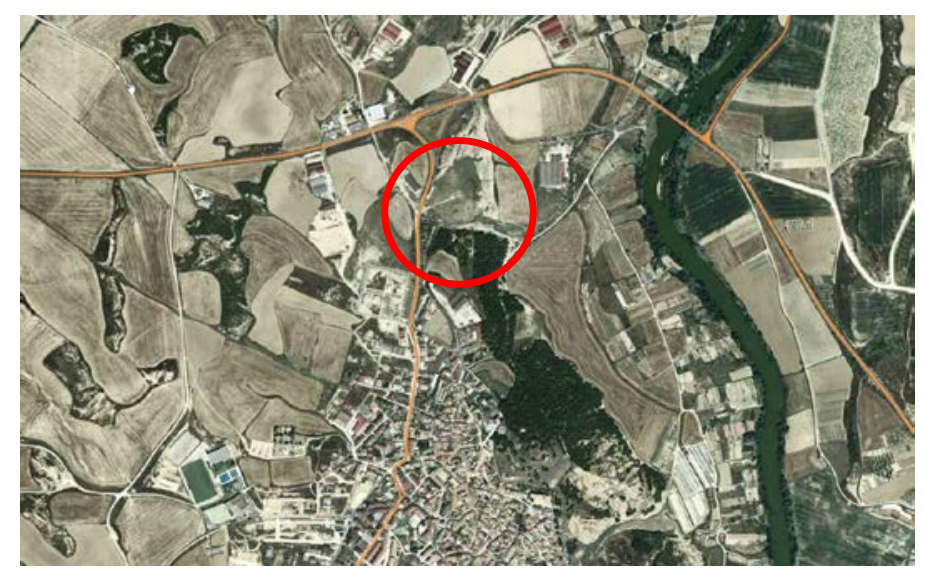

Fig. 9 Localización del parque de los Turrientes, en relación al núcleo urbano

\subsubsection{Nuevas construcciones en el parque de los Turrientes}

Es prioritario contextualizar la bejera reconstruida en el parque con la construcción de otros pequeños edificios agrarios relacionados estrechamente con la explotación de la bejera. Estas nuevas edificaciones ayudarán a interpretar y comprender las tareas apícolas y la relación de las abejas con los recursos del medio natural. Se trata de:

I. Caseta: Es una pequeña construcción de apenas 2 × 2 metros de planta, cuyo uso principal era el resguardo de agricultores y pastores ante condiciones climáticas adversas o rigurosas. Se construye en piedra del lugar, generalmente en forma de sillarejo irregular o grandes losas. Las fábricas presentan rejuntados pobres, generalmente de barro. El espacio se cubre con falsa cúpula de grandes lajas de piedra, voladas unas sobre otras hasta cerrar el espacio central. Esa falsa cúpula se recubre de arcilla y tierra, creando una cubierta vegetal. Como modelo para la construcción de esta caseta se toman referencias de otras ya existentes. 

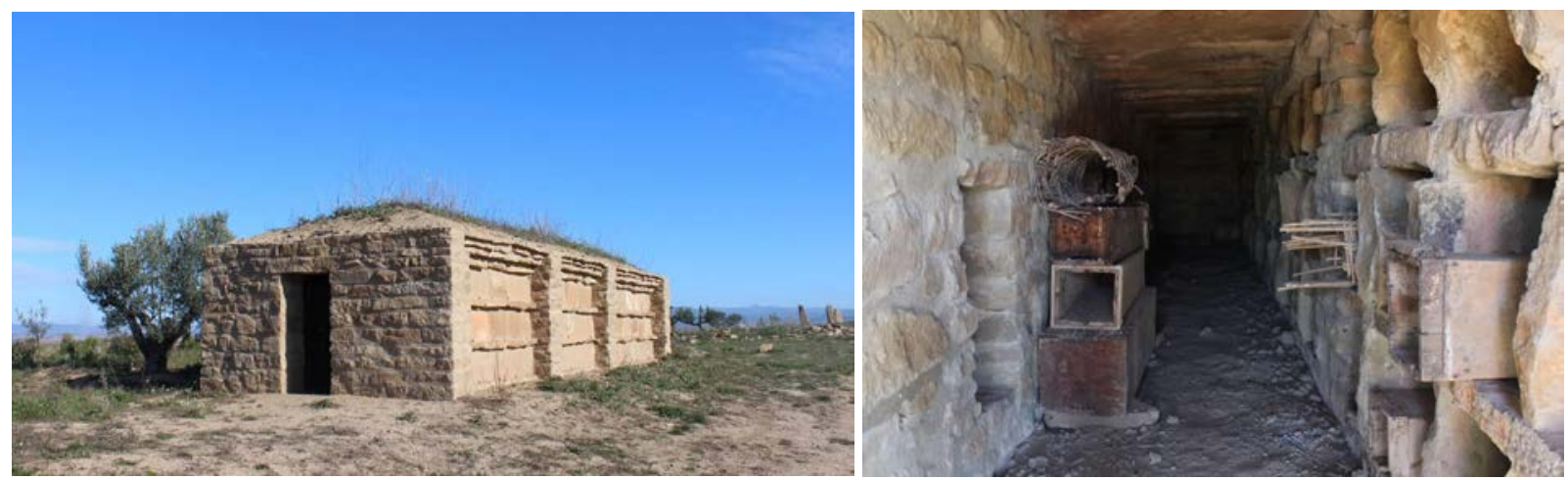

Figs. 10 y 11 Bejera reconstruida en el parque de los Turrientes

II. Celdas de aclimatación: Son construcciones similares a las bejeras, pero sin espacio interior cerrado. Permiten alojar colmenas que puedan ser colonizadas por nuevos enjambres. Se situaban cercanas a las bejeras de manera que, cuando la población de la bejera creciera y se dividiera, el grupo que abandonara la bejera se asentara en estas celdas de aclimatación. En ocasiones se construían otros alojamientos más pequeños, para alojar una o pocas colmenas que pudieran ser colonizadas, en puntos estratégicos próximos o incluso más alejados de la bejera. Son los llamados ventureros.

III. Pozo: Generalmente se trataba de un depósito de almacenamiento de agua que diera servicio a la bejera. Cuando no existían fuentes naturales o masas de agua próximas a la bejera, se recogía y almacenaba el agua de lluvia, conduciendo hacia el pozo las escorrentías.

\subsubsection{Actuaciones de revegetación del parque de los Turrientes}

Se proponen las siguientes actuaciones paisajísticas concretas encaminadas a consolidar la vegetación autóctona en relación con el objetivo interpretativo del paisaje cultural de las bejeras:

I. Formación de talud en torno a la bejera, mediante aporte de material drenante, formación de talud y aporte de tierra vegetal. Va encaminado a la formación y consolidación del suelo.

II. Reforestación, que contempla las tareas de formación de pradera natural y la plantación de arbolado adecuado al lugar y uso interpretativo del mismo: Trasplante de los olivos próximos a la bejera; Suministro y plantación de chopos de tamaño pequeño, para con ellos crear un tamiz de separación entre el paraje y la carretera de acceso al municipio; Plantación de almendros: árboles de flor que están directamente relacionados con la actividad apícola; Y revegetación de talud mediante la plantación de plantas de monte bajo (tomillo u otros) autóctono, abonado y riego si fuera necesario.

\subsubsection{Obras complementarias}

El proyecto contempla la adecuación de una zona de aparcamiento para vehículos para visitantes del espacio de Interpretación. La superficie destinada a este uso será una superficie no pavimentada (sub-base drenante y superficie compactada de gravas naturales), integrada en el conjunto del parque. También se incorpora la canalización de abastecimiento de agua para el riego inicial y para boca desde el cercano parque de La Memoria. 


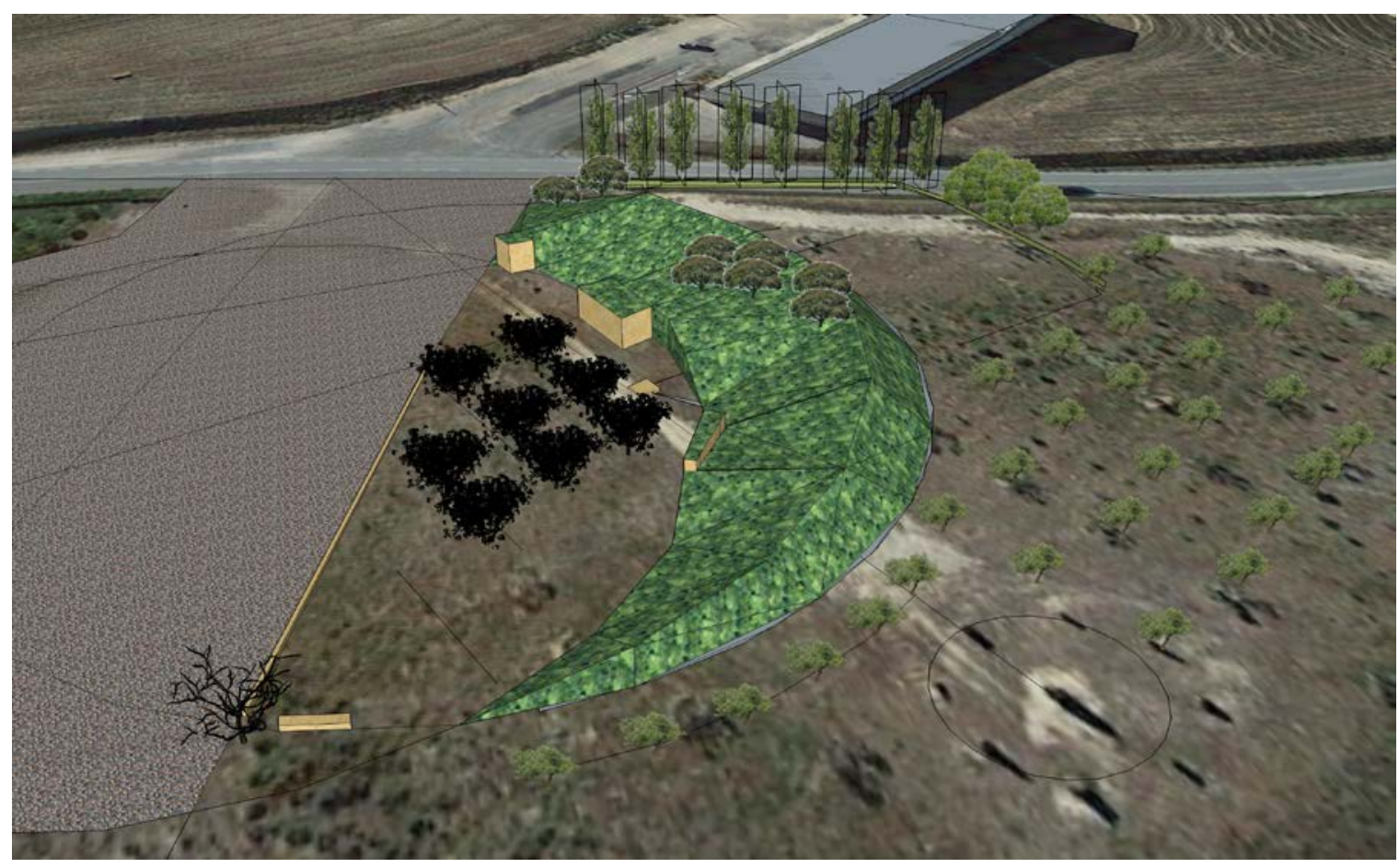

Fig. 12 Infografía con la reordenación del parque de los Turrientes

\subsection{Rutas por el Paisaje cultural de las Bejeras de Larraga: Señalética e identidad gráfica}

El Espacio de interpretación de las Bejeras de Larraga en el parque de los Turrientes es también el origen de diferentes rutas que permiten conocer algunas de las bejeras existentes en el término municipal.

Con este objetivo se han colocado una serie de señales indicativas, señalizando dichas rutas. El diseño de esta señalética (Fig. 14) mantiene una unidad gráfica con los paneles explicativos que se colocan en el parque de los Turrientes, de manera que son fácilmente identificables. En el parque de los Turrientes se contempla la situación de paneles interpretativos relacionados con:

- Las bejeras y su entorno ambiental y social.

- La Cañada Real y otras actividades en el Paisaje cultural de las Bejeras.

- Las bejeras en el territorio: información de las rutas.

Las rutas se señalizan atendiendo a factores de localización, estado de conservación, distancia y tiempo empleado, conexión con otras rutas y caminos principales, medio de transporte (a pie, bicicleta, vehículo de motor) e interés paisajístico y patrimonial.

En un primer momento, se plantearon 3 recorridos paisajísticos principales, en torno a tres ejes que se indican en la figura 13. Estos tres recorridos ofrecen la posibilidad de llegar a enlazarse o conectarse entre sí. Por otra parte, no agotan la totalidad de las bejeras, dejando abierta la posibilidad de ampliación.

Finalmente se optó por concentrar los esfuerzos en un primera ruta circular que aglutinó 7 bejeras. Estas siete son representativas de la variedad constructiva y paisajística del conjunto. 

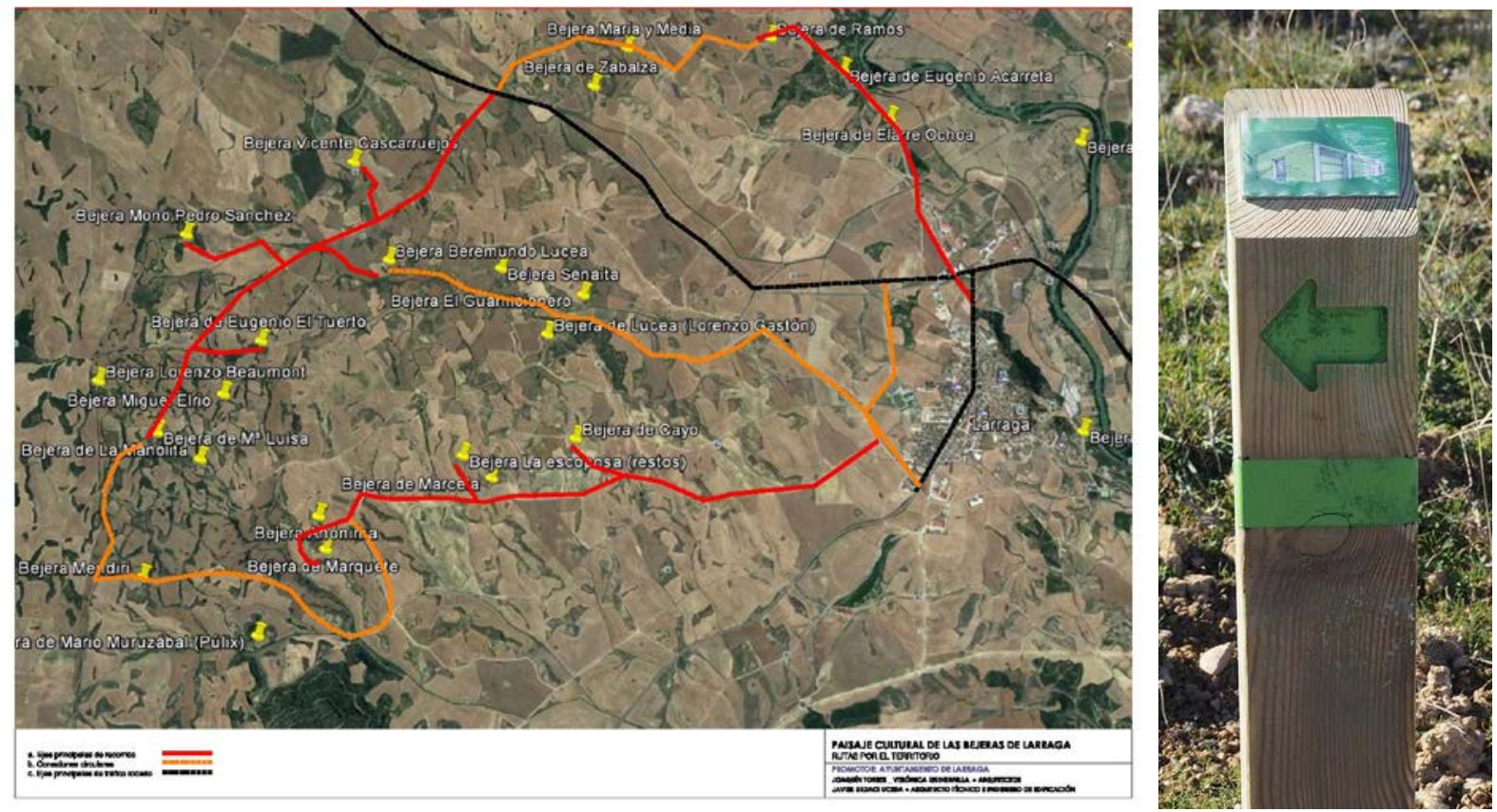

Fig. 13 Rutas principales y su conexión

Fig. 14 Señalética del recorrido

\subsection{Rutas por el Paisaje cultural de las Bejeras de Larraga: Restauración arquitectónica}

Debido al precario estado de conservación de algunas de las bejeras fácilmente accesibles desde los recorridos señalizados, se hace necesaria una intervención arquitectónica en estas construcciones con el objetivo de frenar su deterioro, recuperar su estado original y favorecer su puesta en valor.

El propio proyecto de recuperación arquitectónica favorece además el mantenimiento de formas de construir ligadas al territorio que corren serio peligro de desaparecer: el uso de la piedra, morteros tradicionales, etc.

La intervención arquitectónica planteada no busca actuar en todas y cada una de las bejeras existentes, sino centrarse en aquellas actuaciones de mayor urgencia o importancia. De esta forma quiere ser motor y referente para impulsar el mantenimiento y conservación de estas construcciones ${ }^{4}$.

Se trabajó en colaboración con el Ayuntamiento de Larraga para conseguir fondos que permitieran llevar a cabo el proyecto presentado, con la idea de que se pudiera emprender a lo largo del año 2017. Fruto de este esfuerzo, el proyecto ha contado con financiación del Fondo Europeo Agrícola de Desarrollo Rural a través del programa Leader, y del Gobierno de Navarra conforme a las Estrategias de Desarrollo Local Participadas de la Zona Media (Medida 19 del PDR Navarra 2014-2020).

\subsection{Acciones de difusión y divulgación}

El proyecto sirve de punto de partida para la llamar la atención a los propios habitantes de Larraga y hacerles partícipes de este legado. También busca fortalecer en los propietarios de las bejeras el sentimiento de posesión de algo valioso y, por lo tanto, implicarlos directamente en su mantenimiento, conservación y, por qué no, explotación de estos recursos.

Se programaron varias excursiones abiertas para visitar las bejeras, con bastante afluencia de público. Es reseñable el papel que las redes sociales han jugado en estas convocatorias.

\footnotetext{
${ }^{4}$ De hecho, en 2019 ya se ha actuado en otras bejeras, como la de Senaíta, siguiendo los criterios aquí señalados y el ejemplo físico de las restauradas en el proyecto.
} 


\section{Retos futuros}

Actualmente se continúa avanzando en la documentación y catalogación de las bejeras y sus construcciones auxiliares; en clarificar su propiedad, en algunos casos, y en articular los instrumentos más adecuados para velar por su conservación. Pero a su vez, se pretende trabajar en un plan de difusión, con un doble enfoque hacia los habitantes del municipio y hacia el exterior, conscientes de que sólo desde el conocimiento se puede valorar el patrimonio.

A pesar de que queda mucho por hacer, se han dado los primeros pasos en la vinculación del patrimonio con sus destinatarios. La recientemente creada Asociación Gardacho, para fomentar el cuidado y protección del medio ambiente en Larraga, ha tomado partido por este tema. Una iniciativa privada ha puesto nuevamente en uso una de estas construcciones, dotándola de colmenas y abejas, para uso comercial de la miel y la cera. Iniciativas como esta devuelve su pleno sentido a las bejeras y abre la vía de una posible recuperación de la actividad propia para estas construcciones, lo que significaría el más interesante camino para su conservación.

\section{Conclusiones}

Las bejeras constituyen una extensa serie de elementos edificados distribuidos por el territorio, definitorios de la estrecha relación de la actividad humana con el medio natural, y cargados de valores arquitectónicos, constructivos, paisajísticos, documentales y significativos para los habitantes de Larraga. Forman parte del patrimonio cultural de la localidad.

Su estado de conservación requería una intervención urgente en muchos casos, para evitar su total pérdida. Sin embargo, su recuperación efectiva debía abordar otros frentes de acción: el estudio, la difusión y el interés sobre este patrimonio, como garante de mejor conocimiento y aprecio. En ambos frentes, la colaboración público-privada es determinante.

Con objetivos globales a corto, medio y largo plazo, la primera fase de intervención llevada a cabo, se ha concretado en dos ejes: la creación de un foco que facilite la correcta interpretación del paisaje; y el establecimiento de una red señalizada de recorridos que permitan descubrir estos elementos dentro del paisaje. Se ha abordado desde una doble componente de restauración arquitectónica y paisajística y de componente social y divulgativa. El resultado es que se siguen dando pasos con más interés e ímpetu.

\section{Referencias}

Carrión Gútiez, A. (Coord.) et al. (2015). Plan Nacional de Paisaje Cultural. Secretaría General Técnica, Subdirección General de Documentación y Publicaciones. Madrid: Ministerio de Educación, Cultura y Deporte.

UNESCO. (2012). Carta Iberoamericana del Paisaje Cultural. II Encuentro de Paisajes culturales, Cartagena de Indias: UNESCO.

Consejo de Europa. (2000). Convenio Europeo del Paisaje, Florencia.

Ley Foral 14/2005, de 22 de noviembre. (2005). Ley Foral de Patrimonio Cultural de Navarra, publicada en BON n. ${ }^{\circ} 141$ de 25 de noviembre, 2005.

Nieto García, J. M. (2011). Las bejeras en Larraga. Pamplona: Ed. J.M. Nieto.

UNESCO. (1992). Convención del Patrimonio Mundial de la UNESCO. París. 